\title{
Juan José Carreras y otros, Historia de la música en España e Hispanoamérica: 5. La música en España en el siglo XIX. Madrid: Fondo de Cultura Económica, 2018, 752 pp.
}

"El siglo XIX inventó la música española". Con esta lacónica y provocadora frase comienza Juan José Carreras la redacción de este volumen, el último de la serie que Fondo de Cultura Económica ha dedicado al estudio de la historia de la música en España e Hispanoamérica. Haciendo honor al proyecto editorial global, Carreras presenta aquí un volumen general de introducción al período. Sin embargo, como se deduce de su iconoclasta frase inicial, también nos ofrece un proyecto intelectual francamente renovador, con el que el editor se muestra dispuesto a sentar las bases para una nueva comprensión del período, alejada de las convenciones más tradicionales de la musicología nacionalista española.

Como en todos los volúmenes de la serie, el presente libro ha sido editado y redactado en su mayor parte por un único autor, Juan José Carreras, aunque ha contado también con colaboraciones puntuales de otros especialistas como Celsa Alonso, Cristina Bordas, Teresa Cascudo y José Máximo Leza. A pesar de su evidente cercanía, no muestra grandes vínculos narrativos o metodológicos con el volumen correspondiente al mismo período en Hispanoamérica, sujeto a un ámbito geográfico y político mayor y condicionado por un número mucho más variado y disperso de fuentes, y menos aún con el volumen, más enciclopédico e irregular, destinado al análisis del siglo XX en España. Tanto en su tono narrativo como en su aspiración general, puede conectarse con mucha más facilidad con los dos volúmenes estrictamente anteriores, los dedicados al siglo XVII y XVIII, y muy especialmente al último, con el que se superpone de manera natural.

Historiar la música del siglo XIX, no obstante, presenta algunas dificultades específicas que hacen de ésta una iniciativa sustancialmente diferente a la de cualquiera de estos volúmenes. Por un lado, el carácter cambiante del siglo, la modernización acelerada y desigual del territorio y la multiplicación exponencial de fenómenos musicales de muy distinta naturaleza, hacen que la realidad del período sea especialmente poliédrica y difícil de condensar. Por otro lado, el siglo XIX es un siglo vivo en su repertorio e ideología. Nuestros auditorios y centros de enseñanza siguen girando, en gran medida, en torno a concepciones y obras de esta época, respetando en no pocos casos las mismas consignas ideológicas, autonomía del arte, metafísica de la música instrumental, culto al artista, nacionalismo, etc., que se establecieron en este tiempo.

A esto hay que añadir que la historiografía musical sobre el período presenta dos importantes problemas conceptuales. Por un lado, ha estado profundamente condicionada por el peso ideológico del nacionalismo español, lo que ha conducido a una visión reduccionista y altamente aislacionista del repertorio, definido en no pocas ocasiones por la negación -ciertamente inverosímil- de cualquier influencia foránea. Por otro lado, esta visión nacionalista española ha estado contaminada en no pocas ocasiones por una serie de mitos historiográficos, como el del fracaso español o el del congénito cainismo patrio, que ha llevado a muchos autores a asumir afirmaciones tan tajantes como rocambolescas 
sobre el siglo, sin haber hecho un acopio mínimo de fuentes. Como consecuencia de lo anterior, en este campo, ha persistido una tradición historiográfica débil, que ha tendido tanto a la generalización superficial como a la sobreabundancia enciclopédica de datos, al margen de cualquier discurso jerarquizador $u$ organizado. Baste señalar que los precedentes más significativos de este volumen son el de Carlos Gómez Amat, que constituye más una guía sentimental del siglo que un manual de referencia, y el conjunto de artículos editados por Emilio Casares y Celsa Alonso, que, si bien logró aportar algunas novedades esenciales, tampoco consiguió dar una lectura unitaria del período. ${ }^{1}$

Partiendo de este trasfondo, este libro supone un cambio sustancial de perspectiva con respecto a ambos problemas, consolidando una línea que comenzó a ser definida por su editor hace ya más de dos décadas. En sus textos anteriores, Carreras había planteado análisis historiográficos profundos y complejos de los grandes textos de la musicología española, de sus orígenes y condicionantes esenciales y, sobre todo, del peso del nacionalismo en la misma. ${ }^{2}$ Gracias a ello, nuestro autor contaba con las bases conceptuales necesarias para abordar la dura tarea de reconstruir este período, afrontando una necesaria discusión hermenéutica no sólo con los actores implicados en la propia época de estudio sino, sobre todo, con los discursos que sobre el tema le han precedido.

De acuerdo con ello, y estableciendo una distancia metodológica y organizativa considerable con respecto a sus precedentes, este volumen está dividido en dos partes, metodológica y conceptualmente diferenciadas. La primera de ellas, que abarca más de un tercio del total, consta de dos capítulos escritos íntegramente por el editor y aborda cuestiones generales, siguiendo -de acuerdo con sus propias palabras- el modelo de Koselleck y su "historia de los conceptos". La segunda parte tiene un carácter cronológico y divide el siglo en cuatro bloques, correspondientes a los períodos 1790-1830; 18301860; 1860-1890 y 1890-1914. Las referencias intelectuales de este apartado son más variadas, con guiños a las obras clásicas de Carl Dahlhaus, Fabrizio della Seta y los volúmenes de la serie Man and Music, ${ }^{3}$ aunque en su desarrollo se aprecia un admirable abanico de influencias proveniente de diferentes disciplinas, tradiciones e idiomas.

La escritura del libro, como caracteriza al resto de publicaciones de sus autores, es preciosista y compleja, abundante en conexiones con otras disciplinas y con una querencia indisimulada por el diálogo con las principales corrientes musicológicas

\footnotetext{
${ }^{1}$ Carlos Gómez Amat, Historia de la música Española. 5. Siglo XIX (Madrid: Alianza, 1984); La música española en el siglo XIX, ed. Emilio Casares y Celsa Alonso (Oviedo: Universidad de Oviedo, 1995).

${ }^{2}$ A modo de introducción, Juan José Carreras López, "La historiografía artística: la música," Teoría/crítica, 1 (1994): 277-306; "Hijos de Pedrell: la historiografía musical española y sus orígenes nacionalistas (17801980)," Il Saggiatore musicale, 1 (2001): 121-169; Mariano Soriano Fuertes, Historia de la Música española desde la venida de los fenicios hasta el año de 1850 (Madrid: Instituto Complutense de Ciencias Musicales, 2007), V-XXIII; y, Mariano Soriano Fuertes, "Música nacional, historia de un concepto" en El pentagrama político. Ensayos sobre música y nacionalismo, ed. Alfonso Colorado, Mariona Lloret, Enric Ucelay-Da Cal (Barcelona: Edicions N.E., 2016), 27-49

${ }^{3}$ Carl Dahlhaus, La música del siglo XIX (Madrid: Akal, 2014); Fabrizio della Seta, Storia della musica. 9. Italia e Francia nell'Ottocento (Torino: EDT, 1996); The early romantic era: between revolutions, 1789 and 1848, ed. Alexander Ringer (London: Macmillan, 1990); The Late Romantic Era: from the Mid-19th Century to World War 1, ed. Jim Samson (London: Macmillan, 1991).
} 
internacionales. Sin embargo, para emitir un juicio ponderado debemos afrontar una serie de cuestiones metodológicas y conceptuales que conviene delimitar antes de comenzar.

Las últimas décadas se han caracterizado por un enorme debate en torno a los métodos y la finalidad de la historia, así como a la utilidad, o no, del marco del Estado nación para la misma. Producto de este diálogo han surgido propuestas muy diferentes, en ocasiones enfrentadas o incompatibles entre sí. Por otro lado, al escribir una historia de cualquier disciplina artística ésta deberá contemplar, como resumía con elocuencia Carl Dahlhaus, la dualidad entre una "historia" del arte o una historia del "arte", es decir, establecer a priori cuál será el núcleo generador de la narrativa y el foco de atención del escritor. ${ }^{4}$ Finalmente, cabría preguntarse si el presente volumen constituye una historia de la "música española", en cuyo caso conviene definir con precisión qué se entiende por tal, o una historia de "la música en España", con todos los problemas asociados a una definición de ese tipo, entre ellos, la relación entre creación y recepción, la dualidad "música clásica / música popular", la presencia de la capital frente a la periferia o la relación entre música y mercado, por citar sólo algunos de los más candentes.

Ciertamente, algunos aspectos clave de la propuesta que reseñamos, como el espacio o la demarcación geográfica y política del proyecto, venían definidos por la propia propuesta editorial. Por otro lado, pese a su amplitud dentro del conjunto de la colección, un volumen que no llega a las ochocientas páginas no puede ofrecer una lectura exhaustiva de todos los procesos musicales generados en el siglo XIX y tendrá que ser necesariamente selectivo. Como bien señala el propio Carreras, el resultado final de una historia de este tipo tiene que ser una narración coherente que invite al lector a profundizar en el período, no una mera cartografía documental y enciclopédica del siglo.

Por lo que se refiere a la periodización, el editor ha optado por utilizar los marcos de un siglo largo, estableciendo una serie de precedentes en el final del siglo anterior y prolongando el estudio, si bien de una manera más superficial, hasta la segunda década del siglo XX. En este caso, hay que reconocer que, si bien esta definición de procesos de larga duración resulta sugerente y bien fundamentada, lo cierto es que la continuidad entre los fenómenos de finales del siglo XVIII y los procesos desarrollados a partir de la década de 1830 no resulta tan evidente como pudiera parecer. Por un lado, el impacto de la guerra de 1808 fue lo suficientemente fuerte como para cambiar algunos fenómenos de raíz, dando lugar a una estructura social y política nueva cuya dialéctica interna no puede ser entera ni fácilmente subsumida por las categorías intelectuales anteriores. Por otro lado, tampoco parece demostrado que fenómenos musicales aparecidos posteriormente se inspiraran o tomaran sus bases de las propuestas anteriores. De hecho, es más que probable que los principales movimientos musicales generados a partir de 1830 se basaran más en sus equivalentes contemporáneos internacionales que en precedentes autóctonos que ya resultaban de lejana memoria.

En cuanto a la dualidad planteada por Dahlhaus, no cabe duda de que nos encontramos ante una "historia" de la música. El editor ha primado el análisis cultural,

${ }^{4}$ Carl Dahlhaus, Foundations of music history (Cambridge: Cambridge University Press, 1983), 19-33 
conceptual, organizativo y estético sobre el análisis de la música como objeto histórico. En sus propias palabras, el objetivo era construir una historia cultural de la música que pudiera contribuir a una discusión con el resto de disciplinas y sirviera a una base de lectores más amplia (p. 27). Por ello, en la mayor parte del texto se han evitado las listas de autores y obras, así como las descripciones biográficas detalladas, primando en su lugar un acercamiento más institucional, económico o cultural que un análisis propiamente dicho del repertorio. Sin embargo, en este campo existen divergencias importantes entre autores. Así, a pesar de la declaración inicial de intenciones, podemos encontrar largos listados de carácter enciclopédico en el texto de Cristina Bordas sobre las exposiciones internacionales (pp. 607-615) o aproximaciones biográficas ligeramente teñidas de hagiografía en el análisis de Teresa Cascudo en torno a los grandes compositores del período de entresiglos (pp. 678-710).

Desde el punto de vista del encuadre histórico, el análisis que se plantea en el volumen puede conectarse claramente con dos principios bien asentados en la historiografía internacional sobre el período, aunque no citados expresamente: el concepto de "campo" de Bourdieu y la idea de la música como un "mundo de arte" de Becker. ${ }^{5}$ En el primer caso, el editor prescinde en la medida de lo posible de referencias políticas o conexiones con otras artes, vinculando esencialmente los procesos musicales a sus propios condicionantes ideológicos, económicos y organizativos, así como a la relación mantenida con su entorno internacional. En el segundo caso, Carreras entiende desde el principio el campo musical como un "mundo de arte" e incluye dentro de los confines del mismo elementos propios de la historia social (niveles de vida, precios, estructuras comerciales, connotaciones de clase en el repertorio), de la sociología política (análisis ideológico del repertorio) o de los estudios de género (con secciones específicas dedicadas al papel de la mujer). Junto a ellos se incluye un análisis profundo del entorno institucional y legal $\mathrm{y}$, en el caso del teatro, se incluyen elementos de análisis dramatúrgico y escénico.

Probablemente a consecuencia de esta lógica narrativa globalista, el editor ha tomado la decisión de prescindir de las partituras, lo que sin duda beneficia el impacto general del volumen y le permite llegar a un mayor abanico de lectores. Sin embargo, esta es una decisión que no está exenta de polémica. Por un lado, la ausencia de partituras hace que en ocasiones procesos musicales concretos sean difíciles o incluso imposibles de entender. Expresiones comunes en las descripciones musicales, como "armonía wagneriana", no tienen una traducción sonora única y, por tanto, carecen de significación precisa sin ver los procesos específicos sobre los que se asientan. Por otro lado, encontramos descripciones analíticas muy precisas en algunos textos de Teresa Cascudo (pp. 433-441, 569, 696-697), que habrían resultado mucho más claras con la inclusión de la partitura. En este sentido, probablemente resulta más coherente el uso medido y

\footnotetext{
${ }^{5}$ El concepto de "campo intelectual" ha sido objeto de numerosas conceptualizaciones en la obra de Pierre Bourdieu. Una buena antología de textos en castellano al respecto puede verse en Pierre Bourdieu, Campo de poder, campo intelectual. Itinerario de un concepto (Buenos Aires: Montressor, Jungla Simbólica, 2002). Sobre el concepto de "mundo de arte," véase la obra de Howard S. Becker, Art Worlds (Los Angeles: University of California Press, 1982).
} 
significativo de pequeños fragmentos que se utilizaba en el volumen del siglo XVIII de la serie y que contribuían a una mejor comprensión de los fenómenos creativos expuestos.

Por lo que se refiere a la estructura narrativa, el editor ha optado por una concepción lineal y unitaria que evita la dispersión poliédrica e hiperespecializada propia, por ejemplo, de los volúmenes de la Cambridge History of Music, si bien ello no evita que existan diferencias sustanciales de estilo y contenido entre los autores incluidos en el volumen. De forma muy condensada, esa línea narrativa viene determinada por dos grandes ideas que vertebran todo el texto y sirven como principal hilo conductor de la narración: la construcción ideológica de la idea de "música española" a lo largo del siglo, y la introducción y difusión de corrientes musicales internacionales que permitan conectar los procesos españoles con los producidos en el resto de Europa. En el primer caso, la influencia de Kosselleck es evidente, como se puede apreciar en el intento, enormemente novedoso en un texto de estas características, de definir y delimitar las múltiples y contradictorias definiciones de "música española" dentro de su propio contexto discursivo. Igualmente, se aprecia la influencia de Pierre Nora $^{6}$ en el trato preferente dado a los "lugares de la memoria" y a los elementos simbólicos (iconografía, arquitectura monumental, historiografía) que acabaron dando sentido a la idea nacional.

En cuanto a la conexión con lo que ocurrió en el resto de Europa, es especialmente significativa la distinción establecida en el arranque entre la idea de "fracaso", tan cara a la historiografía musical española y fuertemente connotada desde un punto de vista ideológico y moral, y la de idea de "atraso", como principio mensurable e infinitamente más útil desde el punto de vista analítico. De acuerdo con esta última idea, el editor ha prestado una especial atención a los campos musicales que se situaban en el eje de la vida musical europea del momento y que le permiten establecer una comparativa razonable para el caso español: el teatro musical, los conciertos públicos y, en menor medida, la música de salón, si bien otros ámbitos de composición, como la música religiosa, para banda o para baile, son presentados tangencialmente. Del mismo modo, se nos ofrece un análisis de las redes musicales internacionales, tanto de músicos como de ideas, y su papel en la configuración de la vida musical española del siglo XIX, prestando especial atención a la relación, ya fuera de dependencia, rechazo o simbiosis, entre las élites culturales españolas y las de los países que marcaban la pauta a seguir en la Europa del momento. En este campo, habría sido interesante contar con un análisis de los discursos exóticos asociados a la idea de España en el extranjero y de la tesis de Judith Etzion, tan sugerente como poco explorada, sobre el peso que tuvo la "leyenda negra" en estos procesos, si bien esta ausencia puede resultar comprensible por cuestiones de espacio y coherencia discursiva. ${ }^{7}$

\footnotetext{
${ }^{6}$ Pierre Nora, Les lieux de mémoire, 3 vols. (Paris: Gallimard, 1997).

7James Parakilas, "How Spain Got a Soul," en The Exotic in Western Music, ed. Jonathan Bellman (Boston: Northeastern University Press, 1998), 139-192; Samuel Llano, Whose Spain?: Music, Identity and the Hispanistes in Paris, 1909-1929 (New York: Oxford University Press, 2012); Judith Etzion, "Spanish music as perceived in Western music historiography: A case of Black Legend?," International Review of the Aesthetics and Sociology of Music, 29/2 (December 1998): 93-120.
} 
La presencia central de estas dos "ideas-fuerza" hace que la narración sea sólida y didáctica. Por un lado, permite abordar un verdadero diálogo hermenéutico en torno al concepto ideológico más significativo del siglo XIX, el de la "música nacional", mostrando su diversidad semántica y su evolución de una manera precisa y medida. Por otro lado, permite ofrecer una visión del período novedosa y global, que cambia de raíz las perspectivas obsesivamente aislacionistas de los manuales previos y permite encuadrar a España en el contexto internacional musical.

A este respecto, sólo una omisión nos resulta difícil de justificar, si bien es coherente con la lógica narrativa del texto: la de la guerra de 1808. De la escritura del capítulo, se deduce que los procesos iniciados con anterioridad a la contienda tuvieron una continuidad natural, ya fuera tras el fin de las hostilidades, o tras el fin del gobierno de Fernando VII, y, por ello, no se llegan siquiera a nombrar los efectos de la guerra sobre el desarrollo cultural del país. Sin embargo, la guerra de 1808 no fue un hecho histórico ajeno al desarrollo musical nacional, sino una realidad profundamente traumática que afectó a su evolución en al menos tres campos bien definidos. En primer lugar, fomentó la hostilidad de una parte sustancial de los españoles frente a las ideas de la modernidad, asociadas ya de manera indeleble con la brutalidad de las fuerzas extranjeras, napoleónicas o británicas, lo que acabaría legitimando el gobierno despótico de Fernando VII y empujaría a una gran parte de las figuras intelectuales del período al exilio. En segundo lugar, propició una extrema fragmentación y debilidad política en España, que tendría repercusiones internacionales muy severas, incluyendo la pérdida de las colonias $\mathrm{y}$, con ellas, de un inmenso mercado musical. Por último, provocó una hecatombe humana y material, generando una caída demográfica terrible, arruinando los sistemas de comunicaciones internos y destruyendo casi por completo las finanzas públicas. La guerra fue, por tanto, un factor esencial para explicar la escasa prioridad otorgada a la música en los años que siguieron al conflicto, el colapso en determinadas industrias auxiliares fundamentales o la ausencia de una burguesía ilustrada en el primer tercio del siglo, todos ellos elementos abordados en el libro pero desconectados de la que, sin duda, era su causa más evidente.

Finalmente, y haciendo honor al título, estamos ante una historia de la música "en España" en la que se plantea, diríamos que por primera vez, un verdadero equilibrio entre el análisis de procesos de creación y procesos de recepción. Así, se analizan tanto los grandes géneros que se desarrollan en el país, especialmente teatrales, como la recepción de las grandes corrientes internacionales, incidiendo en la relación musical, estética e ideológica entre ambos procesos. En el primer campo, resulta especialmente destacado el análisis que se realiza del nacimiento y difusión de la zarzuela, con una sección concisa pero sumamente acertada en torno a la génesis y el desarrollo del género chico. En el campo de la recepción, se echa en falta un análisis más profundo de la presencia y difusión del repertorio mainstream, esto es, el bel canto italiano y la ópera francesa, si bien se incluyen apartados que resumen la presencia española de Rossini, Beethoven y Wagner, además de autores menos conocidos pero igualmente clave en el desarrollo musical del siglo como Offenbach o Pleyel. Finalmente, aunque la obra tiende por necesidad a centrarse en los procesos musicales generados en Madrid y, en menor medida, en Barcelona, focos principales al fin y al cabo de las novedades musicales producidas en 
España, existe un esfuerzo deliberado por incorporar al discurso las principales ciudades de la periferia, si bien con un espacio necesariamente menor.

En conclusión, podemos afirmar que, aunque tenga alguna omisión significativa, como la guerra de 1808, y contenga pequeñas contradicciones en su narrativa interna, nos encontramos ante un volumen que está destinado a convertirse en la primera referencia de estudio en su campo. En un espacio limitado, el editor ha conseguido dar una perspectiva global y novedosa de elementos esenciales que estaban ausentes en la bibliografía anterior, como el papel de España en el circuito musical internacional, la conceptualización compleja y variable del concepto "música española", el entorno institucional, social y económico en que se desenvolvieron los cambios musicales del siglo y la relación entre procesos de creación y recepción. Todo ello en un permanente diálogo con la propia historiografía del período y en un discurso bien hilvanado que resulta fácil de leer. Ciertamente, como todo volumen que aborde un período tan largo y complejo como éste, el discurso tiene que ser necesariamente restrictivo y realizar omisiones que pueden resultar significativas al lector, pero esas ausencias no cuestionan el edificio conceptual creado por el editor ni quitan mérito a una construcción muy sólida que supone un extraordinario punto de partida para discusiones posteriores.

Francisco Parralejo Masa

Conservatorio Profesional de Música 'Joaquín Villatoro'

http://independent.academia.edu/FranciscoParralejoMasa

parralejo@usal.es

Fecha de recepción: 4 de enero de 2019

Fecha de aceptación: 3 de junio de 2019

Publicación: 30 de junio de 2019

Para citar este artículo:

Francisco Parralejo, "Juan José Carreras y otros, Historia de la música en España e Hispanoamérica: 5. La música en España en el siglo XIX. Madrid: Fondo de Cultura Económica, 2018, 752 pp.”, Historiografías, 17 (enero-junio, 2019): pp. 151-157. 